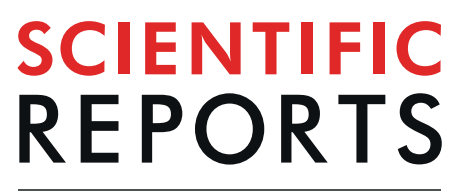

natureresearch

Check for updates

\title{
Preservation of global synaptic excitatory to inhibitory ratio during long postmortem intervals
}

\author{
Pietro Scaduto ${ }^{1,2}$, Adolfo Sequeira ${ }^{3}$, Marquis P. Vawter ${ }^{3}$, William Bunney ${ }^{3}$ \& Agenor Limon ${ }^{1 凶}$ \\ The study of postsynaptic excitation to inhibition (E/I ratio) imbalances in human brain diseases, is \\ a highly relevant functional measurement poorly investigated due to postmortem degradation of \\ synaptic receptors. We show that near-simultaneous recording of microtransplanted synaptic receptors \\ after simulated morgue conditions allows the determination of the postsynaptic E/I ratio for at least \\ $120 \mathrm{~h}$ after death, expanding the availability and use of human diseased tissue stored in brain banks.
}

\begin{abstract}
The excitation to inhibition balance has been defined as the average amount of depolarizing to hyperpolarizing neuronal synaptic currents (global synaptic E/I ratio or just E/I ratio) in a particular brain region ${ }^{1}$. Because the $\mathrm{E} / \mathrm{I}$ ratio emerges from complex processes that are critical for physiological coding by neural circuits ensembles ${ }^{2}$, alterations of this balance have been proposed to underlie neuropsychiatric and neurodegenerative disorders such as schizophrenia, autism, and dementia ${ }^{3,4}$. However, to what extent potential disturbances of the E/I ratio in brain disorders are actually corrected by synaptic scaling ${ }^{5}$, heterosynaptic plasticity ${ }^{6}$ and changes of synaptic function ${ }^{7}$ is not known. Because global synaptic E/I imbalances cannot be implied from observing dysfunction in only one component, simultaneous measurements of excitatory and inhibitory components are necessary to directly assess whether a putative synaptic E/I imbalance has been, or not, corrected by homeostatic processes. Thus, accurate measurement of $\mathrm{E} / \mathrm{I}$ imbalances in human brain synapses is critical to understand the pathophysiology of brain disorders whose major clinical manifestations emerge from abnormal synaptic function. Whereas the E/I ratio has been measured at the neuronal level in animal models, the overall synaptic ratio in a particular region of the brain is still not well known. In humans the E/I ratio is even less understood due to the difficulty to measure the simultaneous activity of synaptic excitatory AMPA receptors (AMPARs) and inhibitory GABA receptors $_{\mathrm{A}}$ $\left(\mathrm{GABA}_{\mathrm{A}} \mathrm{Rs}\right)$ in living people. The reactivation of postmortem tissue by microtransplantation of synaptic membranes (MSM), which allows the electrophysiological analysis of postsynaptic AMPARs and $\mathrm{GABA}_{\mathrm{A}} \mathrm{Rs}^{8-11}$, has opened the possibility to determine $\mathrm{E} / \mathrm{I}$ imbalances in human brains. However, the large variability of ion current responses across microtransplanted cells ${ }^{12-14}$ and the potential degradation of biological activity of ion channels due to postmortem interval (PMI $)^{15}$, has slowed the study of E/I imbalances in disorders involving synaptic alterations. Our initial MSM experiments have shown preservation of synaptic GABA receptors for PMI as long as $29 \mathrm{~h}$ without apparent loss of function in 4 control subjects ${ }^{16}$. Those results prompt us to investigate the limits of the preservation of synaptic receptors, and its potential use to determine the synaptic E/I ratio. In this proof of principle study, we show that the global postsynaptic E/I ratio can be determined from the near-simultaneous

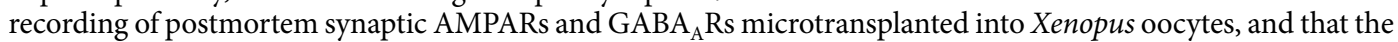
large variability of responses observed when AMPARs or GABARs are studied separately is greatly minimized when the E/I ratio is used instead. We also demonstrate that the E/I ratio is relatively unaffected by PMI when the tissue is stored at cold temperatures even for long periods of time.
\end{abstract}

\section{Methods}

Rat brain cortex. Twenty two adult male Wistar rats, 2 months old, were euthanized at the same time following procedures in accordance with the National Institutes of Health Guide for the Care and Use of Laboratory Animals. The experimental protocols were approved by the IACUC at University of California, Irvine (IACUC: 1998-1388). According to the Requirements for the facilities and operation of mortuaries by the National Pathology Accreditation Advisory Council (NPAAC) the morgue temperature range for humans is $2-6^{\circ} \mathrm{C}^{17}$. Therefore,

\footnotetext{
${ }^{1}$ Department of Neurology, Mitchell Center for Neurodegenerative Diseases. School of Medicine. University of Texas Medical Branch at Galveston, Galveston, USA. ${ }^{2}$ Department of Biomedicine, Neuroscience and Advanced Diagnostics, Division of Human Physiology, University of Palermo, 90134, Palermo, Italy. ${ }^{3}$ Department of Psychiatry \& Human Behavior, University of California Irvine, Irvine, CA, 92697, USA. ${ }^{\bowtie}$ e-mail: aglimonr@utmb.edu
} 
a.

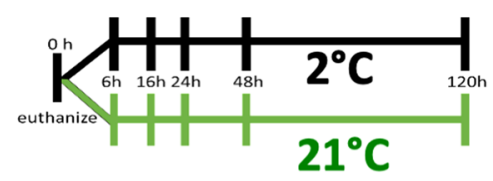

C.

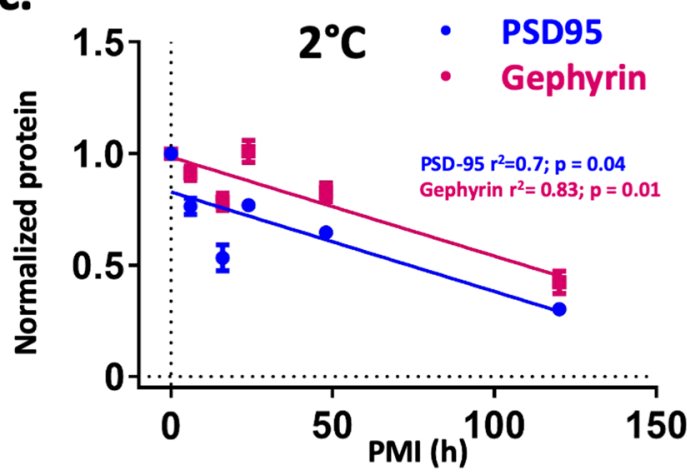

e.

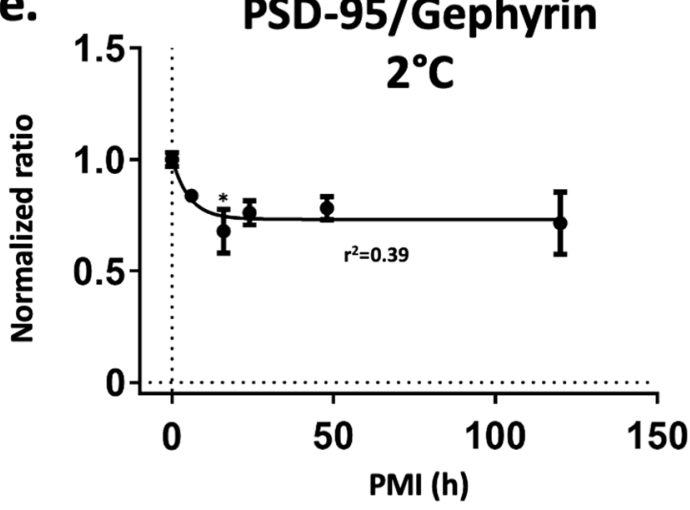

b.
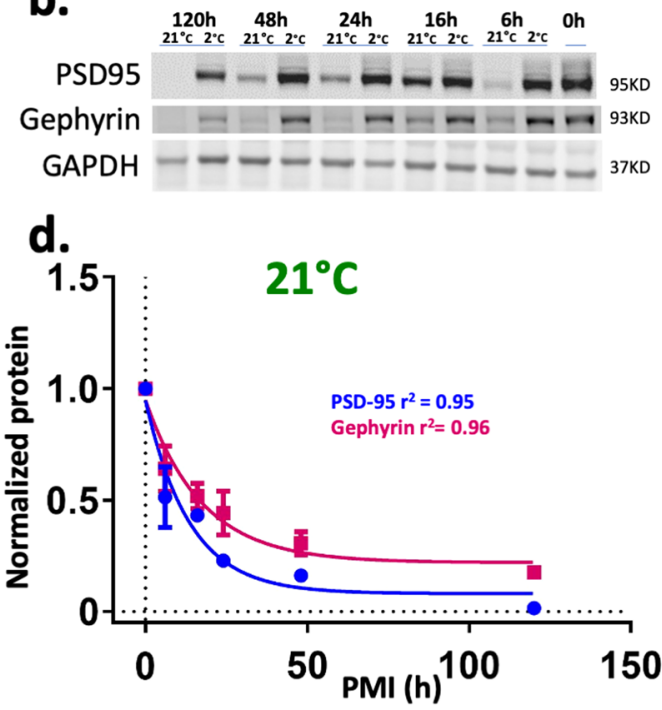

f.

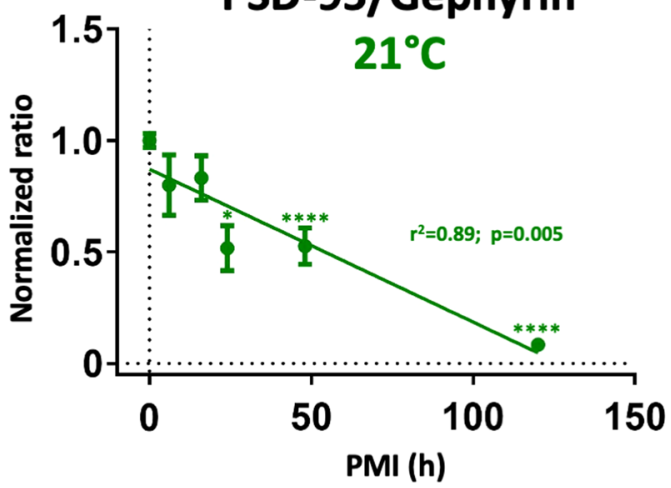

Figure 1. Morgue temperature reduced the rate of synaptic protein degradation and preserved the PSD-95/ gephyrin ratio. (a) Schematic of experimental schedule. (b) Representative Western blots of excitatory (PSD-95), inhibitory (gephyrin) postsynaptic markers, and GAPDH that was used as an internal control in synaptosomeenriched P2 fractions. The bands were cropped from the full-length gel displayed in supplementary Fig. 4a. (c-d) Synaptic protein levels of PSD-95 and gephyrin at $2{ }^{\circ} \mathrm{C}$ and $21^{\circ} \mathrm{C}$. Linear regressions $\left(2{ }^{\circ} \mathrm{C}\right)$ and one phase decay $\left(21^{\circ} \mathrm{C}\right)$ functions were used to fit the means of gephyrin and PSD-95 protein level along the PMI. (e-f) The PSD-95/gephyrin ratio shows temperature-dependent relationships across time. At simulated morgue conditions, and after an initial reduction, the PSD-95/gephyrin ratio is preserved at least after $120 \mathrm{hrs}$ after death. The $\mathrm{E} / \mathrm{I}$ ratio was fitted with one phase decay at $2^{\circ} \mathrm{C}$ and with a linear regression at $21^{\circ} \mathrm{C}$. Here and in next figures the $\mathrm{p}$ values and $\mathrm{r}^{2}$ are shown for linear regresions; non-linear regressions show the $\mathrm{r}^{2}$. Data are reported as means \pm SEM. $* \mathrm{p}<0.05, * * * \mathrm{p}<0.0001 . \mathrm{N}=8,7,5,4,4,4$ gel bands for $0,6,16,24,48,120 \mathrm{~h}$ at $2^{\circ} \mathrm{C}$ and $\mathrm{N}=8,7,5,4,4,4$ gel bands for $0,6,16,24,48,120 \mathrm{~h}$ at $21^{\circ} \mathrm{C}$ (Supplementary Table 1). Statistical test is a One-way ANOVA followed by multiple comparison Dunnett's test $v s$ the control group (time 0 ).

euthanized rats were kept at $2{ }^{\circ} \mathrm{C}$, to simulate morgue conditions, or $21^{\circ} \mathrm{C}$, to simulate room temperature, for different time intervals: $0,6,16,24,48$, or $120 \mathrm{~h}(\mathrm{~N}=2$ rats for each experimental point; 22 rats in total). The body temperature of the rats was measured by putting a small digital temperature logger (ibutton; thermochron; Baulkham Hills, Australia) outside the chest of the animals. At the specified time brains were surgically removed; the cortex was isolated, frozen by immersion in liquid nitrogen and stored at $-80^{\circ} \mathrm{C}$ (Fig. 1a).

Human tissue. The right frontal hemisphere from a 39 years old male control subject ( $\mathrm{PMI}=15 \mathrm{hrs})$ was obtained postmortem from the University of California Irvine Brain Bank (UCIBB) after obtaining verbal and written consent from next of kin according to guidelines of the Institutional Review Board approval. The UCIBB protocols for human brain tissue were approved by the Institutional Review Board at University of California, Irvine (HS\#1997-74). A psychological autopsy was completed based on family informant information, medical and psychiatric records, toxicology reports, and the subject's medication history. The UCIBB autopsy protocol is based largely on procedures validated by Kelly and $\mathrm{Mann}^{18}$, and includes questions concerning the decedents' demographics, medical history, psychiatric symptoms, medication use, hospitalizations, substance use, physical health. The human brain dissection and freezing protocol is described in detail elsewhere ${ }^{19}$. Briefly, after 
collection, frontal cortex samples were either frozen in isopentane at $-40^{\circ} \mathrm{C}(\mathrm{PMI}=15 \mathrm{~h})$ or keept at $4{ }^{\circ} \mathrm{C}$ at different time intervals $(18,21,27,39,63$, and $87 \mathrm{~h})$ before freezing. This temperature is in the middle of the range recommended by the NPAAC. It is important to note that that due to the limited amount of human brain donations of "control" people, we limited the use of brain specimens in experiments where degradation and loss of function is expected. For this reason, we only include specimens from one human brain and most of our work was done with brain tissue from rats.

Synaptosomes isolation. Synaptosomal enriched preparations were extracted from $50 \mathrm{mg}$ of human DLPFC or $60 \mathrm{mg}$ of dissected rat cortex using Syn-PER reagent protocol (Thermo Scientific, Rockford, IL) following the manufacturer instructions. We pooled brain tissue from the 2 rats used for each condition to obtain a single preparation per time point and temperature. Three fractions (S1, P1, P2) from each preparation were isolated, stored at $-80^{\circ} \mathrm{C}$, and used for downstream protocols as specified below. The $\mathrm{S} 1$ fraction contains soluble cytosolic elements. The P2 fraction is enriched in synaptosomes. The P1 fraction, which contains mostly nuclei, myelin, and large non-homogenized tissue, was used as a reference for synaptosomes enrichment in P2 fractions by Western Blot analysis. All the procedures of centrifugation were performed at $4{ }^{\circ} \mathrm{C}$ using proteinase inhibitors (Thermo fisher, cat \#A32955) to reduce proteolysis and denaturation. P1 and P2 fractions were re-suspended in Syn-Per buffer solution and the amount of protein was quantified by DeNovix QFX fluorometer instrument (DeNovix Inc. Wilmington, USA) and Qubit reagents (Invitrogen, cat\# Q33212).

Western blotting. Twenty $\mu$ g of proteins from P2 fractions were run in a polyacrylamide gel (Invitrogen precast gradient gels $4-12 \%$ bis-tris plus) at $155 \mathrm{~V}$. To reduce the variability multiple proteins were detected by re-blotting the membrane with different antibodies and without a stripping protocol between blottings. Proteins were transferred from the gel to a nitrocellulose membrane (Invitrogen, cat\#LC2000) and unspecific blocking was reduced by incubating membranes for $1 \mathrm{~h}$ at room temperature with Odyssey blocking buffer (LI-COR Biosciences - U.S.). Next, membranes were treated for $1 \mathrm{~h}$ at room temperature, or overnight at $4{ }^{\circ} \mathrm{C}$, with the following primary antibodies. Mouse anti-synaptophysin (Abcam cat\# ab8049, dilution 1:2000), mouse anti-PSD-95 antibody (Thermo Fisher cat\# MA1-045, dilution 1:2500), rabbit anti-gephyrin antibody (Abcam cat\# ab32206, dilution 1:1600), rabbit anti-NeuN antibody (Abcam, cat\#ab177487, rabbit, and dilution 1:2000), rabbit anti-GAPDH antibody (Abcam cat\# ab9485, rabbit, and dilution 1:3000). GAPDH was selected because is minimally affected by $\mathrm{PMI}^{20}$. To visualize the primary antibody membranes were incubated with fluorescent secondary antibody (Li-cor anti-rabbit cat\#926-32213 and anti-mouse cat\#926-68072 dilution 1:2000 for both) and imaged with an Odyssey infrared imager (Li-Cor Odyssey 9120 Infrared Imaging System, Lincoln, Nebraska USA). The intensities of the bands were analyzed with Image J software (Rasband WS, ImageJ, U.S. National Institutes of Health, Bethesda, MD, http://rsb.info.nih.gov/ij/, 1997-2017). Statistical significance was evaluated by One-way ANOVA comparing the values at different time points vs the control (the lowest PMI) within the same temperature. For post hoc analysis we used Dunnett's multiple comparison test (JMP version 14; SAS Institute, Cary, NC).

Analysis of pH. Human and rat brain cortex $(60 \mathrm{mg})$ were homogenized at $4{ }^{\circ} \mathrm{C}$ in $600 \mu \mathrm{L}$ of ddH $\mathrm{d}_{2} \mathrm{O}$ at $7 \mathrm{pH}$ $\left(\mathrm{w} / \mathrm{v}\right.$ 1:10) as previously described ${ }^{21}$. After 30 minutes, the $\mathrm{pH}$ was measured using a micro $\mathrm{pH}$ electrode and the Accumet AE150 pH Benchtop Meter (Thermo Fisher Scientific Inc.). Three readings per sample were taken. Intraclass correlation coefficient [ICC] was calculated using R studio software, ICC $=0.999,95 \%$ confidence interval [CI] within samples.

Isolation and injection of RNA. Total RNA was extracted from the P2 fraction from each rat experimental group using PureLink RNA Mini Kit (Invitrogen by Thermo Fisher Scientific). Extracted RNA was quantified using NanoDrop 2000/2000c and was later injected into the oocytes $(2 \mathrm{mg} / \mathrm{mL})$. Electrophysiological recordings of oocytes injected with total RNA were performed $24 \mathrm{~h}$ after injection. Quality of isolated RNA was determined by RIN value using an Agilent 2100 bioanalyzer.

Microtransplantation of synaptic membranes (MSM) and TEVC. For MSM experiments $50 \mathrm{~nL}$ of P2 fractions at $2 \mu \mathrm{g} / \mu \mathrm{L}$ were injected into stages V-VI Xenopus Laevis oocytes as previously described ${ }^{11}$ and recorded by TEVC the day after the microinjection $(20-28 \mathrm{~h})$. Briefly, frogs were placed in anesthetic solution $(0.17 \% \mathrm{MS}-222)$ for $10-15 \mathrm{~min}$ before extracting the ovaries; following procedures in accordance with the National Institutes of Health Guide for the Care and Use of Laboratory Animals, the IACUC at the University of California, Irvine (IACUC: 1998-1388), and at the University of Texas Medical Branch at Galveston (IACUC:1803024). Oocytes were isolated and defolliculated by carefully stirring them in a solution containing $2 \mathrm{mg} / \mathrm{mL}$ collagenase for $2 \mathrm{~h}$ at $30^{\circ} \mathrm{C}$; then, oocytes were transferred to a Petri dish containing Barth's solution [88 mM NaCl, $1 \mathrm{mM} \mathrm{KCl}, 0.41 \mathrm{mM} \mathrm{CaCl} 2,0.82 \mathrm{mM} \mathrm{MgSO} 4,2.4 \mathrm{mM} \mathrm{NaHCO} 3,5 \mathrm{mM}$ HEPES (pH 7.4)], and placed in a temperature-controlled environment at $16^{\circ} \mathrm{C}$ for $24 \mathrm{~h}$ as has been previously reported ${ }^{12,13,22}$. Stage V-VI oocytes were manually separated and placed in a fresh Barth's solution for injection of synaptosomal enriched membranes. P2 fractions, harboring synaptic receptors, were suspended in sterile distilled water and sonicated to create small proteoliposomes that can fuse to the oocytes' extracellular membrane ${ }^{11}$. For TEVC experiments microelectrodes were filled with $3 \mathrm{M} \mathrm{KCl}$ and resistance of the microelectrodes ranged from 0.5 to 3.0 M $\Omega$. Piercing and recording took place in a chamber (volume $\approx 0.1 \mathrm{ml}$ ) continuously perfused $(5-10 \mathrm{ml} / \mathrm{min}$ ) with Ringer's solution [ $115 \mathrm{mM} \mathrm{NaCl}, 2 \mathrm{mM} \mathrm{KCl}, 1.8 \mathrm{mM} \mathrm{CaCl}_{2}, 5 \mathrm{mM}$ Hepes (pH 7.4)] at room temperature $\left(19-21^{\circ} \mathrm{C}\right)$. Oocytes were voltage clamped to $-80 \mathrm{mV}$ using an Oocyte Clamp OC-725C amplifier. Ion currents were recorded and stored with WinEDR version 2.3.8 Strathclyde Electrophysiology Software (John Dempster, Glasgow, United Kingdom) as previously reported ${ }^{11,13}$. Currents were filtered by Dual variable filter Kemo at $20 \mathrm{~Hz}$. GABA was from Sigma (St. Louis, MO, USA) and kainate from Tocris (Minneapolis, MN, USA). All the drugs were dissolved into Ringer's solution. To estimate the E/I ratio, GABA and kainate were applied once to 

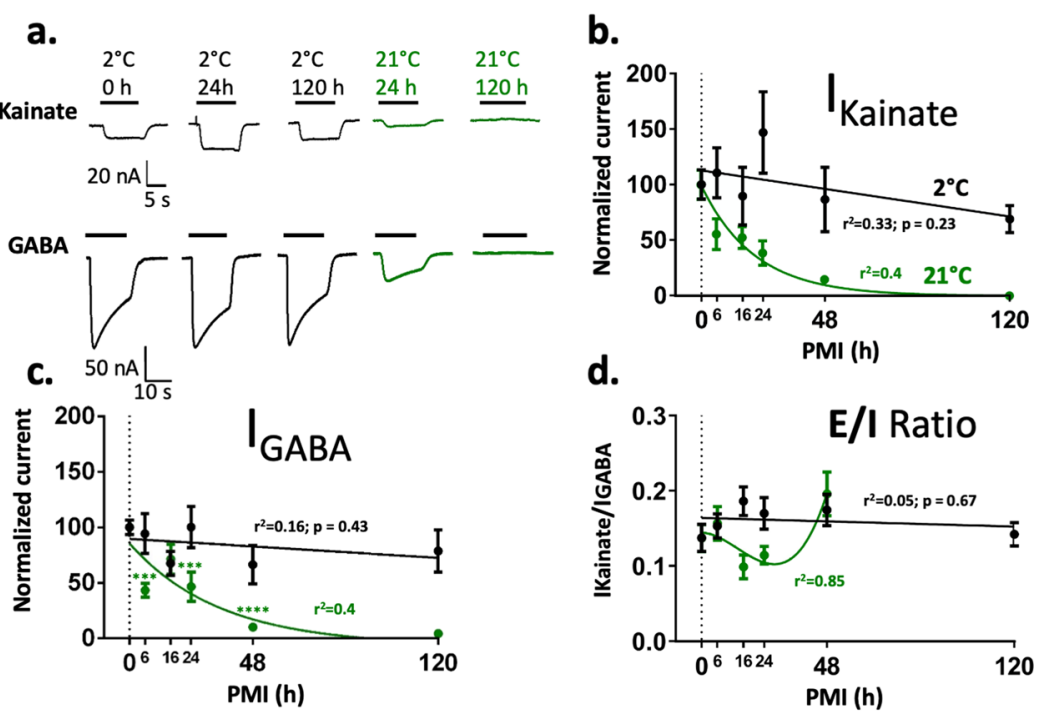

Figure 2. Electrophysiological activity of rat native synaptic receptors is preserved by low temperature. (a) Ion current responses of oocytes microtransplanted with rat synaptic receptors measured by Two-Electrodes Voltage Clamp. (b-c) Maximum current of synaptic receptors normalized to the control $(\mathrm{PMI}=0)$. The currents generated by GABA and glutamate receptors, across PMIs time points, are well preserved at $2{ }^{\circ} \mathrm{C}$ but not at $21^{\circ} \mathrm{C}$ showing significant differences compared to the control (time 0$)(\mathrm{N}=7-11$ oocytes per point, for a detailed description of the number of oocytes in each point, please see supplementary Table 2). Black and green lines represents linear regressions and one-phase decay fits, respectively. (d) The E/I ratio (kainate/GABA current) was calculated only in oocytes that have a clear signal for both GABA and kainate currents. Data shown is the mean \pm SEM of 7-10 oocytes per point; please see supplementary Table 1). No differences were observed across groups. Statistical analysis was done using one-way ANOVA test, followed by Dunnett's multiple comparison test where appropriate. Statistical differences where $* \mathrm{p}<0.05, * * \mathrm{p}<0.01 ; * * \mathrm{p}<0.001 ; * * * * \mathrm{p}<0.0001)$. The mean values of the $\mathrm{E} / \mathrm{I}$ ratio were fit with a linear regression (black) and a third order polynomial equation (green).

each microtransplanted oocyte. Data per each PMI interval are shown as the mean \pm S.E.M of the oocytes tested for each condition. The number of microtransplanted oocytes tested per each condition (technical replicates) was determined by analyzing the magnitude of the effect and the dispersion of the variability as previously reported ${ }^{11}$. For an exact number of the oocytes tested please see supplementary Tables 1-5. Statistical differences were determined by one-way ANOVA, followed by Dunnett's multiple comparisons test between the values at different time points $v s$ the control (the lowest PMI) within the same temperature. Data was considered significant when $p<0.05$. (Graphpad Prism v.8). The $\mathrm{EC}_{50}$ for GABA and kainate was determined by fitting the Hill equation in the form $\mathrm{I}=100 /\left(1+10^{\wedge}\left(\operatorname{LogEC}_{50^{-}}[\mathrm{A}]\right) *\right.$ Hill slope $)$, in which $\mathrm{I}$ is the current amplitude, 100 is the maximum normalized current at the concentration of the agonist $[\mathrm{A}], \mathrm{EC}_{50}$ is the agonist concentration that induces $50 \%$ of the maximal response (Graphpad Prism v.8). The experimental data are shown as the mean \pm S.E.M. Statistical differences were determined by one-way ANOVA and considered significant when $p<0.05$ (Graphpad Prism).

\section{Results and Discussion}

To test the PMI effects on the E/I ratio, 22 adult Wistar rats were euthanized at room temperature $\left(21^{\circ} \mathrm{C}\right)$. The cerebral cortex was immediately removed from 2 rats, snap-frozen in liquid nitrogen and stored at $-80^{\circ} \mathrm{C}$ for downstream applications. These rats were used as controls $(\mathrm{PMI}=0 \mathrm{~h})$. The remaining rats were separated into two groups. One group was kept at room temperature $\left(21^{\circ} \mathrm{C}\right)$ and the other was stored inside a refrigerator $\left(2{ }^{\circ} \mathrm{C}\right)$ to simulate morgue conditions. Cerebral cortices from 2 rats per time point $(6,16,24,48$ and 120 hrs), per group, were surgically removed and snap-frozen in liquid nitrogen. The effects of PMI, from 15 to $87 \mathrm{hrs,} \mathrm{were} \mathrm{also}$ evaluated on tissue samples from the frontal pole of a 39 years old male subject with no history of drug abuse, psychiatric or neurodegenerative disorders. After euthanasia, the rats body temperature fell exponentially from $38^{\circ} \mathrm{C}$ to $21^{\circ} \mathrm{C}$ with a time constant $(\tau)$ of $7.5 \mathrm{hrs}$, and to $2^{\circ} \mathrm{C}$ with a $\tau$ of $4.8 \mathrm{hrs}$ (supplementary Fig. 1a). Measurements of $\mathrm{pH}$ in brain rat cortex homogenates showed that the PMI had no significant effect on $\mathrm{pH}$ when the rat bodies were kept at $2{ }^{\circ} \mathrm{C}$ for up to $120 \mathrm{hrs}$ after death $(\mathrm{pH}=6.80 \pm 0.04 ; F(5,12)=3.096, p=0.0505$; one-way ANOVA; supplementary Fig. 1b). However, a significant acidification at room temperature was observed at 48 and $120 \mathrm{hrs}$ $(\mathrm{pH}=6.74 \pm 0.1 ; F(5,12)=22.53, p<0.0001$; one-way ANOVA followed by Dunnett's multiple comparisons test). The $\mathrm{pH}$ of human brain specimens showed an oscillation across $\mathrm{PMI}$ and we found a significative difference at $18 \mathrm{~h}$ PMI compared to the lowest PMI at $15 \mathrm{~h}(\mathrm{pH}=6.69 \pm 0.07 ; F(6,14)=11.17, \mathrm{p}=0.0001$ one-way ANOVA, followed by Dunnett's multiple comparisons test, supplementary Fig. 1c). Interestingly, the $\mathrm{pH}$ oscillation in rat and human brain tissue stored at morgue temperatures seems to follow a similar pattern across the PMI. In rats we measured RNA integrity (RIN) values that were preserved at $2^{\circ} \mathrm{C}$ for up to $120 \mathrm{hrs}(7.4 \pm 0.37)$, and at $21^{\circ} \mathrm{C}$ for up to $48 \mathrm{hrs}(7.3 \pm 0.39)$ (supplementary Fig. 2a). Synaptic RNA from rats kept at room temperature was highly degraded by $120 \mathrm{hrs}$. 
a.

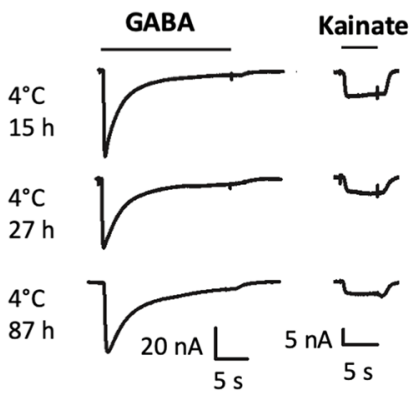

c.

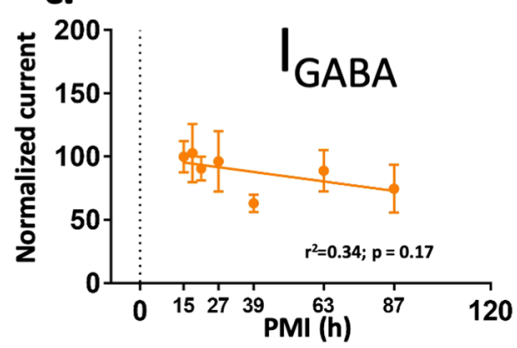

b.
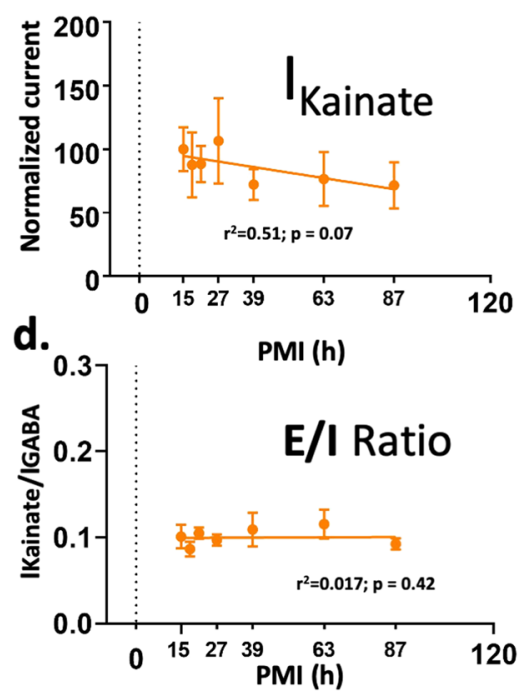

Figure 3. Electrophysiological activity of cortical human native synaptic receptors is preserved by low temperature. (a) Kainate and GABA currents recorded from microtransplanted human synaptic receptors. (b-c) Maximum current of synaptic receptors normalized to the control (initial PMI $=15 \mathrm{~h}$ ). The mean values of maximal currents were fitted using a linear regression. No differences were found using One-way ANOVA test, followed by Dunnett's multiple comparison test $(\mathrm{N}=6-12$ oocytes per point for GABA; $3-11$ oocytes per point for kainate; 3-11 oocytes per point for E/I ratio, see supplementary Table 3 for details of the N per point) (d) E/I ratio of human synapses does not show significant change across PMI.

Degradation level and loss of biological activity of synaptic receptors in synaptosomes were evaluated in synaptosome-enriched P2 membrane preparations. Synaptosome enrichment was determined by the ratio of synaptophysin (Syn) to the nuclear marker NeuN, measured by WB (Syn/NeuN) (supplementary Fig. 3). The Syn/ NeuN ratio in the P2 fraction was increased by $603 \pm 106 \%$ at $2{ }^{\circ} \mathrm{C}$ across all PMIs, and by $622 \pm 278 \%$ at $21^{\circ} \mathrm{C}$ for PMIs up to $48 \mathrm{hrs}$, compared to the P1 fraction. In agreement with the decline of the degradation markers $\mathrm{pH}$ and RIN, samples from brains left for $120 \mathrm{hrs}$ at $21^{\circ} \mathrm{C}$ showed no synaptosome enrichment. With exception of $21^{\circ} \mathrm{C} / 120 \mathrm{hrs}$ samples, similar synaptosome enrichment across different PMIs was observed at $2{ }^{\circ} \mathrm{C}$ and $21^{\circ} \mathrm{C}$ $\left(2^{\circ} \mathrm{C} F(11,26)=4.489, p<0.0008\right.$ and $21^{\circ} \mathrm{C} F(11,20)=4.423, \mathrm{p}=0.002$, one-way ANOVA $)$; although a loss of enrichment trend was observed at $21^{\circ} \mathrm{C}(\mathrm{r}=-0.916$, Pearson's correlation coefficient). WB analysis of the excitatory and inhibitory postsynaptic density proteins, PSD-95 and gephyrin, showed a time-dependent linear reduction of the detection of these proteins at $2{ }^{\circ} \mathrm{C}$ (Fig. 1). Notably, the abundance of both proteins was highly correlated across PMIs indicating a uniform degradation (Fig. 1c); consequently, the PSD-95/gephyrin ratio, at $2{ }^{\circ} \mathrm{C}$, remained borderline constant up to $120 \mathrm{hrs}$ after death $F(5,26)=2.419, p=0.063$ (Fig. 1e). At room temperature the degradation of PSD and gephyrin was better described by a one-phase decay equation (Fig. 1d) and PSD-95 was more affected compared to gephyrin leading to a significantly lower PSD-95/gephyrin ratio after $24 \mathrm{~h}$ at room temperature (Fig. 1f).

An electrophysiological metric of global E/I ratio that is useful to compare brain regions/subjects in health and disease in large population cohorts should be simple to calculate, stable within each subject across experiments, and flexible enough to show pharmacological changes (Fig. 2). Because changes in excitatory plasticity are normally followed by homeostatic changes of inhibitory signaling we decided to allow pharmacological flexibility to the excitatory component of the E/I ratio by activating AMPARs with $100 \mu \mathrm{M}$ kainate, which is near half of the apparent affinity $\left(\mathrm{EC}_{50}\right)$ for kainate in human microtransplanted AMPARs (Figs. 4-5). Kainate is an agonist of AMPARs that keeps the channel in a non-desensitized state allowing consistent recordings of ion currents via AMPARs, produces less intra-subject variation compared to currents elicited by the combination of AMPA + cyclothiazide (CTZ), and due to the low expression of synaptic kainate-type receptors compared to AMPARs in synaptosomes, kainate-induced currents in microtransplanted oocytes reflect the activation of AMPARs $^{23}$. For the estimation of the inhibitory component we used $1 \mathrm{mM} \mathrm{GABA}$ which is a saturating concentration of $\mathrm{GABA}_{\mathrm{A}} \mathrm{Rs}$. Thus, shifts of the E/I ratio reflect changes in the number and activity of excitatory or inhibitory receptors and/or small changes in AMPARs $\mathrm{EC}_{50}$ or large changes of $\mathrm{GABA}_{\mathrm{A}} \mathrm{Rs}_{\mathrm{EC}}$. Figures 2 and 3 show kainate-induced AMPA currents and GABA currents recorded by two-electrode voltage clamp (TEVC) in rats and human microtransplanted native receptors between 20 and $32 \mathrm{hrs}$ post-injection. Non-injected oocytes, as well as oocytes injected with total RNA extracted from rat synaptosomal preparations (supplementary Fig. 2b), were unresponsive to these agonists confirming that ion-currents elicited in injected oocytes were generated by microtransplanted synaptic receptors.

The temperature was critical for preservation of the amplitude of the currents in rats. No statistical differences with the control were found across PMIs at $2^{\circ} \mathrm{C}$, even $120 \mathrm{hrs}$ after death (Fig. $2 \mathrm{~b}-\mathrm{c}$; Kainate, $F(5,106)=2.035$, 
a.
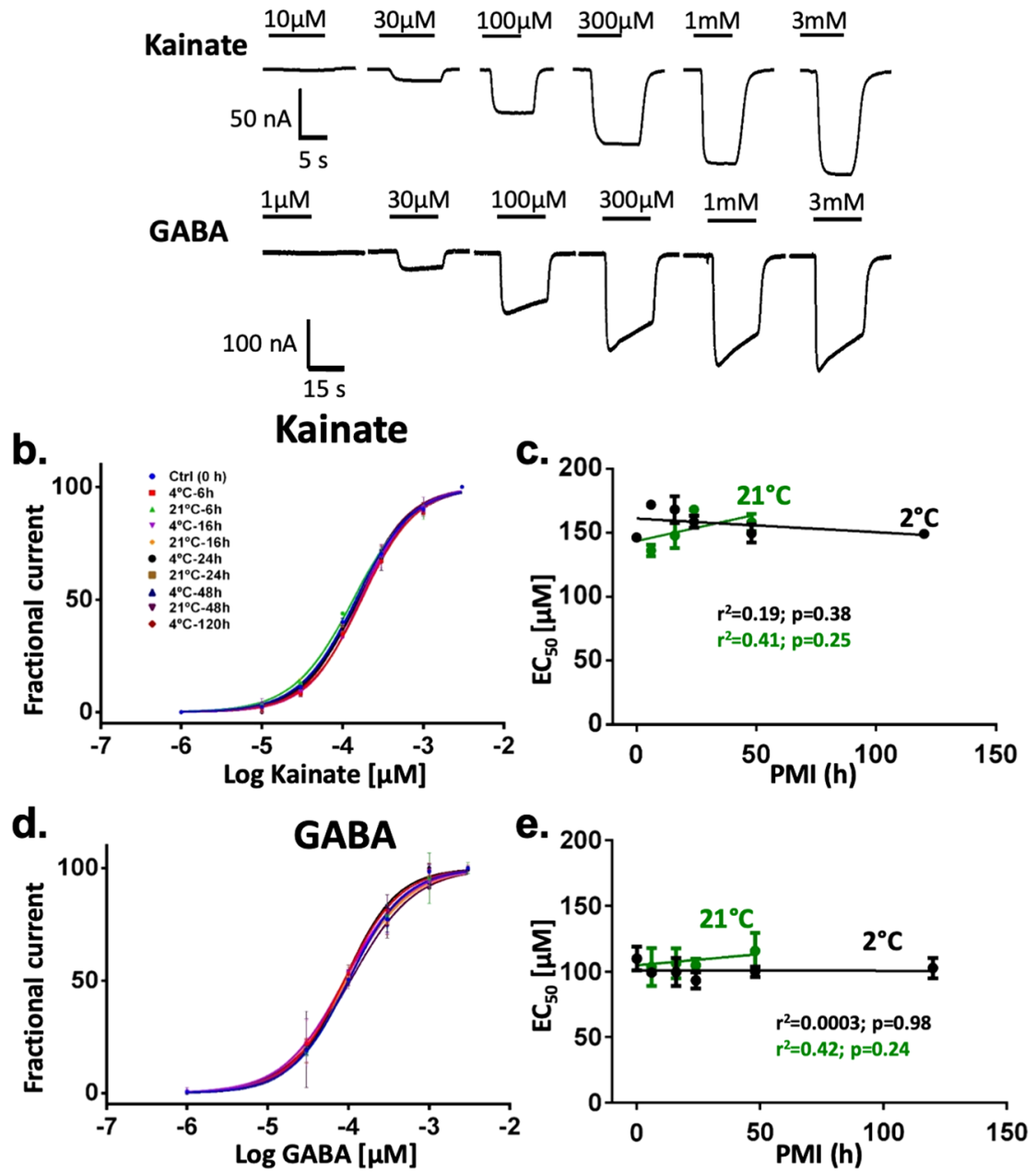

Figure 4. Synaptc receptor affinity is maintained for at least 5 days at $2{ }^{\circ} \mathrm{C}$ and 2 days at $21^{\circ} \mathrm{C}$. (a) Ion currents elicited by different concentrations of GABA and kainate in two oocytes microtransplanted with rat synaptic receptors. Only oocytes with full dose responses and fits with $\mathrm{p}$ values $<0.05$ were included in the analysis. (b-d) Concentration response curves for kainate and GABA (each point was calculated as the mean of 2-3 microtransplanted oocytes; see supplementary Table 4). Curve fitting was done using the Hill equation $\mathrm{I}_{\text {current }}=100 /\left[1+10^{\wedge}\left(\left(\operatorname{LogEC} 5_{50}\right.\right.\right.$-[agonist $\left.]\right) *$ HillSlope $\left.)\right]$. (c-e) $\mathrm{EC}_{50}$ (mean $\left.+\mathrm{SEM}\right)$ was calculated for each doseresponse curve. $21^{\circ} \mathrm{C} / 120 \mathrm{hrs}$ had no current responses. All the groups were fit with a linear regression equation.

$\mathrm{p}=0.080$; GABA, $\mathrm{F}(5,50)=0.9342, \mathrm{p}=0.47$ one-way ANOVA). In contrast, in samples stored at $21^{\circ} \mathrm{C}$ ion currents gradually decreased with longer PMIs. After 6 hrs GABA currents were reduced by $57 \%$ and kainate-induced AMPA currents were reduced by $45 \%$. No currents were observed in $21^{\circ} \mathrm{C} / 120 \mathrm{hrs}$ samples. Remarkably, due to the uniform loss of activity of excitatory and inhibitory synaptic receptors the global E/I ratio was preserved at least up to $120 \mathrm{hrs}$ at $2{ }^{\circ} \mathrm{C}$, and up to $48 \mathrm{hrs}$ at $21^{\circ} \mathrm{C}$ (Fig. $2 \mathrm{~d}$; PMIs at $2^{\circ} \mathrm{C}, F(5,50)=1.077 ; \mathrm{p}=0.38$ and PMIs at $21^{\circ} \mathrm{C} ; F(4,39)=3.791, \mathrm{p}=0.01$ using one-way ANOVA. $21^{\circ} \mathrm{C} / 48 \mathrm{hrs}, \mathrm{p}=0.053 ; 21^{\circ} \mathrm{C} / 24 \mathrm{hrs}, \mathrm{p}=0.94 \mathrm{using}$ Dunnett's multiple comparison). Moreover, the $\mathrm{EC}_{50}$ or slope (Hill coefficient) to kainate and GABA was not significantly affected by PMI or temperature (Fig. 4). Similar findings were observed in the DLPFC samples stored at $4^{\circ} \mathrm{C}$ for different PMIs (Figs. 3 and 5), although the $\mathrm{EC}_{50}$ for kainate at $63 \mathrm{~h}$ was slightly higher than the rest. The biological activity of AMPA and GABA receptors showed a trend toward reduction by $30 \%$ after $87 \mathrm{hrs}$ (Fig. 3b-c, AMPA $F(6,33)=0.2973, \mathrm{p}=0.93$; GABA $F(6,41)=0.6263, \mathrm{p}=0.71)$ but the $\mathrm{E} / \mathrm{I}$ ratio was preserved (Fig. $3 \mathrm{~d}$ ). These results strongly indicate that the variability of the E/I ratio is minimal compared to the measurements of excitatory or inhibitory components studied in isolation, and it is highly preserved across extremely large PMIs when the tissue is stored at morgue temperature.

It is important to note that our approach uses synaptic membranes that contain a mixed population of synapses, from different neuronal types; therefore, global changes of the E/I may be only able to detect severe alterations of the excitatory or inhibitory components, such as those observed in severe psychiatric and neurological disorders. State-dependent temporary changes of the E/I balance, or small alterations, could not be detected with this approach; Nevertheless, the global E/I also provides a way to normalize electrophysiological and pharmacological parameters of excitatory, or inhibitory, components using a within subject metric in future studies. 
a.
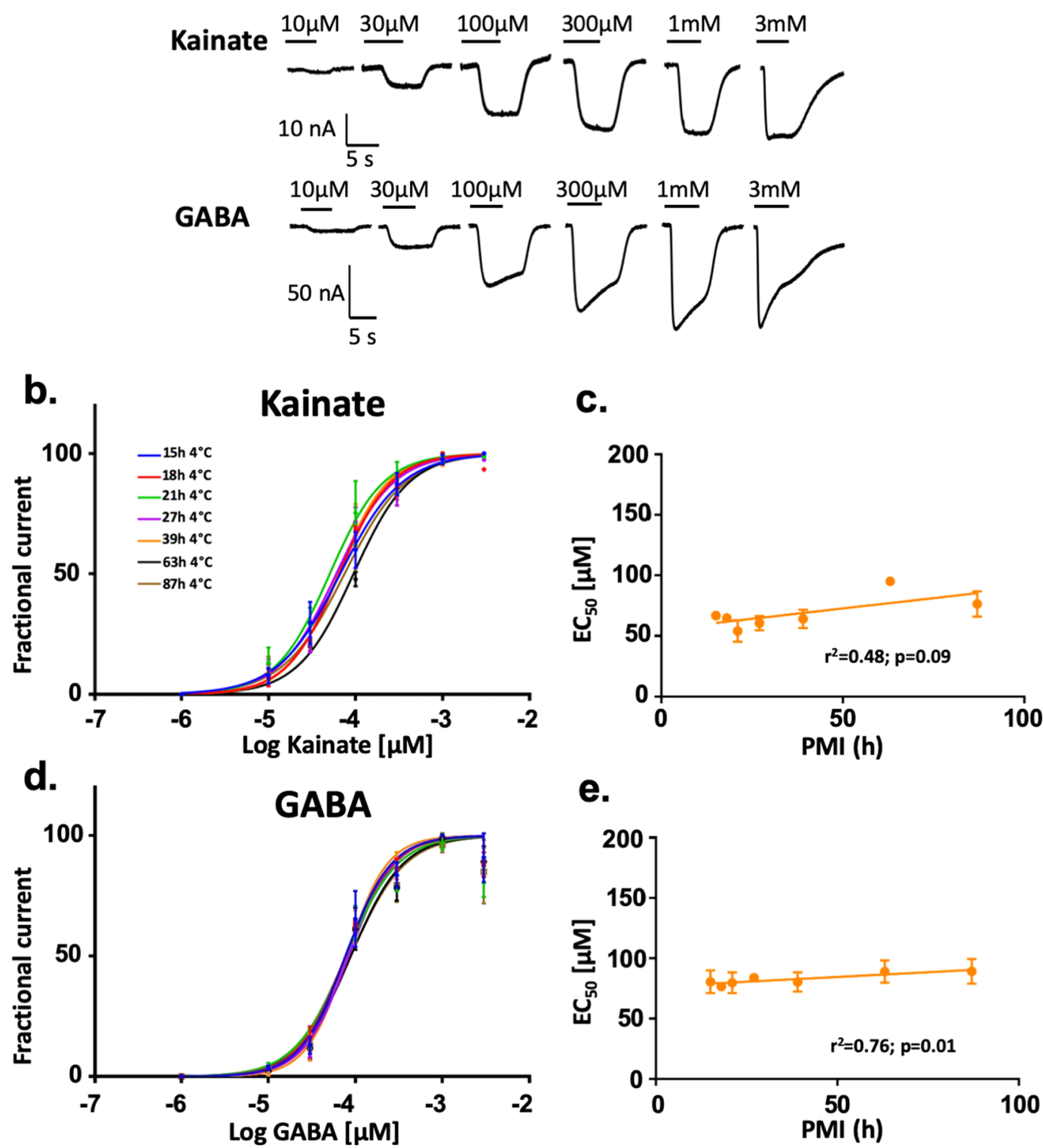

e.

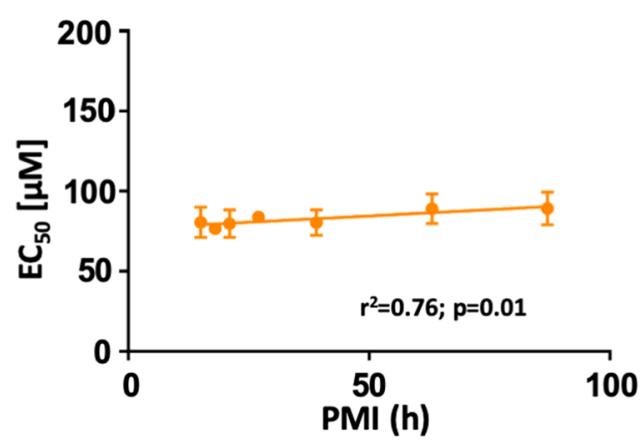

Figure 5. Human native synaptic receptors affinity is maintained for at least $87 \mathrm{~h}$ of PMI at morgue temperature. (a) Human native microtransplanted GABA and glutamate receptors responses at different PMI $(15,18,21,27,39,63,87 \mathrm{~h})$. (b-d) Concentration response curves for kainate and GABA (each point was calculated as the mean of 2-3 microtransplanted oocytes; see supplementary Table 5). Only oocytes with full dose responses and fits with $\mathrm{p}$ values $<0.05$ were included in the analysis. Curve fitting was done using the Hill equation $\mathrm{I}_{\text {current }}=100 /\left[1+10^{\wedge}\left(\left(\operatorname{LogEC} \mathrm{C}_{50}\right.\right.\right.$-[agonist] $\left.\left.) * H i l l S l o p e\right)\right]$. (c-e) $\mathrm{EC}_{50}$ calculated for each dose-response curve. All the groups were fit with linear regression.

Our results provide strong support for the feasibility of electrophysiological and pharmacodynamic studies of the synaptic receptors responsible for the synaptic E/I ratio, using the invaluable tissue that is stored in brain banks over the world and in situations in which long PMIs are still unavoidable.

Received: 22 November 2019; Accepted: 4 May 2020;

Published online: 25 May 2020

\section{References}

1. Vogels, T. P., Sprekeler, H., Zenke, F., Clopath, C. \& Gerstner, W. Inhibitory plasticity balances excitation and inhibition in sensory pathways and memory networks. Science 334, 1569-1573, https://doi.org/10.1126/science.1211095 (2011).

2. Zhou, S. \& Yu, Y. Synaptic E-I Balance Underlies Efficient Neural Coding. Front Neurosci 12, 46, https://doi.org/10.3389/ fnins.2018.00046 (2018).

3. Busche, M. A. \& Konnerth, A. Impairments of neural circuit function in Alzheimer's disease. Philos Trans R Soc Lond B Biol Sci 371, https://doi.org/10.1098/rstb.2015.0429 (2016). 
4. Gao, R. \& Penzes, P. Common mechanisms of excitatory and inhibitory imbalance in schizophrenia and autism spectrum disorders. Curr Mol Med 15, 146-167, https://doi.org/10.2174/1566524015666150303003028 (2015).

5. Turrigiano, G. G., Leslie, K. R., Desai, N. S., Rutherford, L. C. \& Nelson, S. B. Activity-dependent scaling of quantal amplitude in neocortical neurons. Nature 391, 892-896, https://doi.org/10.1038/36103 (1998).

6. Froemke, R. C. Plasticity of cortical excitatory-inhibitory balance. Annu Rev Neurosci 38, 195-219, https://doi.org/10.1146/annurevneuro-071714-034002 (2015)

7. Turrigiano, G. Homeostatic synaptic plasticity: local and global mechanisms for stabilizing neuronal function. Cold Spring Harb Perspect Biol 4, a005736, https://doi.org/10.1101/cshperspect.a005736 (2012).

8. Bernareggi, A. et al. Characterization of GABA(A) receptors expressed in glial cell membranes of adult mouse neocortex using a Xenopus oocyte microtransplantation expression system. J Neurosci Methods 198, 77-83, https://doi.org/10.1016/j.jneumeth.2011.03.011 (2011).

9. Mazzo, F. et al. Reconstitution of synaptic Ion channels from rodent and human brain in Xenopus oocytes: a biochemical and electrophysiological characterization. J Neurochem 138, 384-396, https://doi.org/10.1111/jnc.13675 (2016).

10. Sanna, E. et al. Expression of native GABAA receptors in Xenopus oocytes injected with rat brain synaptosomes. J Neurochem 67, 2212-2214, https://doi.org/10.1046/j.1471-4159.1996.67052212.x (1996).

11. Limon, A. et al. Electrophysiological evaluation of extracellular spermine and alkaline $\mathrm{pH}$ on synaptic human GABAA receptors. Transl Psychiatry 9, 218, https://doi.org/10.1038/s41398-019-0551-1 (2019).

12. Limon, A., Reyes-Ruiz, J. M. \& Miledi, R. Microtransplantation of neurotransmitter receptors from postmortem autistic brains to Xenopus oocytes. Proc Natl Acad Sci USA 105, 10973-10977, 0804386105 [pii]10.1073/pnas.0804386105 (2008).

13. Limon, A., Reyes-Ruiz, J. M. \& Miledi, R. Loss of functional GABA(A) receptors in the Alzheimer diseased brain. Proc Natl Acad Sci USA 109, 10071-10076, https://doi.org/10.1073/pnas.1204606109 (2012).

14. Murenzi, E., Toltin, A. C., Symington, S. B., Morgan, M. M. \& Clark, J. M. Evaluation of microtransplantation of rat brain neurolemma into Xenopus laevis oocytes as a technique to study the effect of neurotoxicants on endogenous voltage-sensitive ion channels. Neurotoxicology 60, 260-273, https://doi.org/10.1016/j.neuro.2016.04.004 (2017).

15. Siew, L. K., Love, S., Dawbarn, D., Wilcock, G. K. \& Allen, S. J. Measurement of pre- and post-synaptic proteins in cerebral cortex: effects of post-mortem delay. J Neurosci Methods 139, 153-159, https://doi.org/10.1016/j.jneumeth.2004.04.020 (2004).

16. Limon, A. D., et al. Electrophysiological evaluation of extracellular spermine and alkaline $\mathrm{pH}$ on synaptic human GABAA receptors. Translational Psychiatry, Accepted, in press (2019).

17. NPAAC. Requierements for the facilities and operation of mortuaries; 978-1-74241-952-7. (National Pathology Accreditation Advisory Council 2013)

18. Kelly, T. M. \& Mann, J. J. Validity of DSM-III-R diagnosis by psychological autopsy: a comparison with clinician ante-mortem diagnosis. Acta Psychiatr Scand 94, 337-343, https://doi.org/10.1111/j.1600-0447.1996.tb09869.x (1996).

19. Jones, E. G. et al. A method for fixation of previously fresh-frozen human adult and fetal brains that preserves histological quality and immunoreactivity. J Neurosci Methods 44, 133-144, https://doi.org/10.1016/0165-0270(92)90006-y (1992).

20. Blair, J. A. et al. Individual Case Analysis of Postmortem Interval Time on Brain Tissue Preservation. PLoS One 11, e0151615, https://doi.org/10.1371/journal.pone.0151615 (2016).

21. Glausier, J. R., Konanur, A. \& Lewis, D. A. Factors Affecting Ultrastructural Quality in the Prefrontal Cortex of the Postmortem Human Brain. J Histochem Cytochem 67, 185-202, https://doi.org/10.1369/0022155418819481 (2019).

22. Miledi, R. A calcium-dependent transient outward current in Xenopus laevis oocytes. Proc R Soc Lond B Biol Sci 215, 491-497, https://doi.org/10.1098/rspb.1982.0056 (1982).

23. Zeppillo, T. et al. Functional impairment of cortical AMPA receptors in schizophrenia. Schizophrenia Research. In Press.

\section{Acknowledgements}

The research was supported by NIA grant R21AG053740 (A.L.), NIMH R01MH097082 and American Foundation for Suicide Prevention (AFSP) grants (AS), NIMH research grant R01MH085801 (M.P.V.), and NIMH research grant R21MH113177 (A.L., M.P.V.)., and the Amon G. Carter Foundation funds to A.L.

\section{Author contributions}

A.L. conceived and designed the study; P.S. and A.L. conducted research; A.S., W.B. and M.P.V. provided unvaluable human tissue, all authors contributed to data interpretation and co-authored the manuscript.

\section{Competing interests}

The authors declare no competing interests.

\section{Additional information}

Supplementary information is available for this paper at https://doi.org/10.1038/s41598-020-65377-3.

Correspondence and requests for materials should be addressed to A.L.

Reprints and permissions information is available at www.nature.com/reprints.

Publisher's note Springer Nature remains neutral with regard to jurisdictional claims in published maps and institutional affiliations.

Open Access This article is licensed under a Creative Commons Attribution 4.0 International License, which permits use, sharing, adaptation, distribution and reproduction in any medium or format, as long as you give appropriate credit to the original author(s) and the source, provide a link to the Creative Commons license, and indicate if changes were made. The images or other third party material in this article are included in the article's Creative Commons license, unless indicated otherwise in a credit line to the material. If material is not included in the article's Creative Commons license and your intended use is not permitted by statutory regulation or exceeds the permitted use, you will need to obtain permission directly from the copyright holder. To view a copy of this license, visit http://creativecommons.org/licenses/by/4.0/.

(C) The Author(s) 2020 